\title{
Narrar la escuela: masculinidades y movimiento estudiantil en Al sur de la Alameda
}

\author{
Dámaso Rabanal Gatica \\ Universidad Austral de Chile \\ damaso.rabanal@uach.cl
}

Miren cómo sonrien los presidentes cuando le hacen promesas al inocente.

Miren cómo le ofrecen al sindicato

este mundo y el otro los candidatos.

Miren cómo redoblan los juramentos, pero después del voto doble tormento.

Miren el hervidero de vigilante

para rociar de flores al estudiante.

Miren cómo relumbran carabineros

Para bacerle premios a los obreros [...]

Miren cómo sonríen, angelicales,

miren como se olvidan que son mortales

Violeta Parra, Miren cómo sonríen

Violeta Parra pregona y desarrolla una voz de alerta, declarada y evidente, que las voces de muchos(as) han cantado para dar sentido al sinrazón y la distancia entre la política y la sociedad e incluso, permitiéndose ser suspicaz, es posible decir que es un desplazamiento antojadizo y conveniente de las autoridades con respecto a sus gobernados. Hoy, en el centenario de la artista y aproximado cincuentenario de esta canción, seguimos cantando las penurias oportunistas en la política contemporánea.

Si continuamos en la senda de la cultura dialogada la canción "El baile de los que sobran" de Los Prisioneros sufre un giro desde algunas experiencias electorales del 2016, pues los sujetos que residen en las zonas del despojo donde han sido desplazados por los designios del poder y las decisiones sociopolíticas, aparecen en el diseño social inesperadamente haciendo a 'los que sobran', a esos muchxs otrxs, los protagonistas de la historia.

El domingo 23 de octubre del 2016, en una funesta competición partidista por sentarse en el trono de hierro de las municipalidades del país, en la ciudad de Valparaíso, el alcalde electo Jorge Sharp se declara ganador del proceso eleccionario 


\section{Adiós a las armas}

Despatriarcar América desde la cultura

enunciando un discurso impetuoso e improvisado desde el colegio de profesores de la ciudad. De sus palabras resalto la primera expresión: "se acabó el duopolio" ("El independiente Jorge Sharp"), problematizando y declarando que los ejercicios del poder heredado por los años en este "país dividido para siempre", como diría Lemebel, ha conseguido concretar una vía alternativa para socializar los ejercicios del poder. Fuera del Colegio de Profesores(as) menciona que será la gente quien decida y gestione los diseños políticos, sociales y culturales locales, en una intención democratizadora de su cotidianeidad, para así renunciar a las acciones biopolíticas que las dos falanges históricas han dispuesto para las personas de esta nación.

En una interesante decisión, distanciándose de la política del show, el alcalde electo enuncia su participación como autoridad en el diseño social porteño desde un escenario improvisado, libre de ostentación, acompañado de músicos, cantantes populares, la comunidad gritando consignas como "se siente, se escucha, arriba los que luchan", estableciendo un discurso de orientaciones biopoéticas y dialogadas con las personas presentes, para generar un trayecto de organizaciones y colectividades que aunaron esfuerzos para sustentar la vía política alternativa ganadora.

Insisto en que la sede porteña del colegio de profesores como lugar de enunciación integradora en la ciudad es un gesto clave donde decir "se acabó el duopolio" es, a su vez, "se acabó el funcionamiento tradicional de la dominación” y discute simbólicamente la construcción de los sujetos mediados por el aparato ideológico escuela, posicionando este gobierno colectivo y socializado como el acceso o inicio de una resignificación del sentido ideológico de lo que la escuela -desde Foucault y Althusser- ha instalado coercitivamente. Es un lugar de intenciones transformadoras que favorezcan múltiples formas de comprender la colectividad.

Insisto en que la sede porteña del colegio de profesores como lugar de enunciación integradora en la ciudad es un gesto clave donde decir "se acabó el duopolio" es, a su vez, "se acabó el funcionamiento tradicional de la dominación" y discute simbólicamente la construcción de los sujetos mediados por el aparato ideológico escuela, posicionando este gobierno colectivo y socializado como el acceso o inicio de una resignificación del sentido ideológico de lo que la escuela -desde Foucault y Althusser- ha instalado coercitivamente. Es un lugar de intenciones transformadoras que favorezcan múltiples formas de comprender la colectividad.

Es así como la propuesta biopoética y la disidencia sociopolítica, en términos de Rubí Carreño, abren un espacio para que la ciudadanía participe en las programaciones de sus vidas, instalando la oportunidad y el empoderamiento como variables fundamentales en la tradicional vida dominada de los cuerpos y subjetividades nacionales. ${ }^{1}$ Esta acción articuladora de biopoética y disidencia en el discurso inaugural de Sharp, es un correlato de las iniciativas de numerosos objetos culturales

1 Hago referencia a los textos de Rubí Carreño: Leche amarga: violencia y erotismo en la narrativa chilena del siglo XX y Av. Independencia. Literatura, música e ideas de Chile disidente. 
y literarios que consideran los imaginarios escolares ficcionalizados, pues los creadores elaboran su acción política-cultural para instalar una intención removedora y renovadora de las conciencias anestesiadas de los lectores posdictatoriales.

Sabemos que la escuela opera como el aparato ideológico (Althusser) fundamental para los ejercicios del poder desde la hegemonía política que prefigura (Bourdieu), el marco social donde conviven y se desarrollan las personas. En este sentido, las formas de comprender la escuela dialogan con las disposiciones del poder que viajan y se construyen por medio de las representaciones e imaginarios, sin embargo, la permanencia de la representación se desestabiliza con el avance del tiempo, dando paso a nuevxs sujetxs y subjetividades que no ingresan y/o no desean pertenecer al modelo social ofrecido por la disposición hegemónica.

Si pensamos en las novelas de posdictadura, esta resignificación de la forma de constituirse sujeto es mayormente abrupta y traumática con respecto a las violencias que la dictadura ha realizado sobre ellxs, aumentando ese deseo de no pertenecer, porque asumir la representación es asumir la programación conveniente del poder. Las novelas Ciencias Morales de Martín Kohan, Space Invaders de Nona Fernández y Al sur de la alameda de Lola Larra y Vicente Reinamontes, son producciones culturales que tensionan la forma tradicional de comprender la escuela dominadora y, en su referencia al escenario educativo, proponen la necesidad de comprender la violencia a través de tres opciones interpretativas y a la vez heterotópicas de la sociedad, estas son: visibilizar el trauma, evidenciar la frustración, y la oportunidad liberadora desde la organización y la autonomía.

En términos de visibilización y diseños de la agresión, Ciencias Morales presenta un contexto escolar ordenado, higiénico y dogmado que responde a las dinámicas de la dictadura. El poder se moviliza sobre sujetos subalternizados, representándolos como subjetividades pasivas que se pueden modelar de acuerdo a los deseos hegemónicos. Por su parte, en Space Invaders de Nona Fernández, el proyecto creativo avanza entregando algunas luces de una posibilidad distinta a la coerción al considerar el ingreso de los estudiantes como agentes políticos activos, sin embargo, la escuela representada reproduce un sistema de dominación similar a la novela de Kohan. La novela de Fernández evidencia una frustración, pues los(as) estudiantes salen al espacio público a instalar las demandas en medio de marchas, pero el telón de fondo deja entrever que ellos se mueven con baja conciencia y empoderamiento. La marcha se vuelve desfile y esos sujetos estudiantiles tienen incorporado en sus cuerpos el ritmo de la dictadura, omnipresente y destructora de cualquier proyecto político alternativo. 


\section{Adiós a las armas}

Despatriarcar América desde la cultura

\section{Al sur de la Alameda: masculinidades al pizarrón entre la literatura y la política}

"Sucede que me canso" menciona Neruda en uno de sus textos más conocidos. Sabemos cuál es exactamente, pues nuestro cerebro, automatizado por las cosas risibles que Nicanor Parra ironiza en su poema "Los profesores", nos lanza a la lengua el título que el poeta ha determinado para su texto: "Walking around". Decir "sucede que me canso" en voz de hombre del siglo XX y anterior, es un abrupto paso a la zona incómoda de la vulnerabilidad masculina que socialmente no debe mostrarse, cuestionarse y exhibirse, pues los mandatos de la masculinidad hegemónica (Connell) no hacen posible las concepciones de debilidad para los sujetos que se hacen llamar hombres. Por supuesto, cualquier otra diversidad, porque en ese concepto entramos todos(as), incluso los hombres, pueden cansarse, disminuyendo su posición de poder por ese respiro.

"Sucede que me canso" es la lectura alternativa para decir "sucede que me indigno" en el siglo XXI, pues indignarse es desestabilizar el poder que ha dicho que no puedo cansarme, en el marco de una sociedad de control (Foucault) abrupta y productiva donde quien se agota no es aprobado. Si consideramos esta lectura paralela entre cansancio e indignación, es posible revisar diferentes sujetos(as) que han sido etiquetados como molestia para el sistema y por ende caen en las zonas del despojo, siendo desplazados, como si "el baile de los que sobran" de Los Prisioneros fuera la metafórica denuncia musical de las subalternidades, en este caso, estudiantiles.

En este entramado lógico donde dialogan las instituciones, las subjetividades estudiantiles son emplazadas al escenario cotidiano para modelar en ellas lo que se ha decidido de acuerdo con la propuesta hegemónica. A saber, los(as) estudiantes deberán lidiar con formas de representación que los posicionan como sujetos recipiente (conductismo) que deben aprender, entre silencio y rigor, las formas "correctas" para desenvolverse en el mundo público y más radicalmente en Chile, para "ser útiles en la sociedad". Es evidente que esta visión instalada de los(as) estudiantes los deja situados en las esquinas donde la mordaza social los ha desplazado, esgrimiendo sobre su representación los rasgos que caracterizan a personas de baja participación social, confundiendo la juventud con inexperiencia anuladora de toda posible opinión, como si fuesen un grupo subalterno (Spivak) sin opinión o que sobrellevan la política del "no estar ni ahî".

Esta representación estudiantil ha liderado diferentes procesos sociopolíticos en Chile y Latinoamérica, permitiendo que la voz ${ }^{2}$ de ellos(as), en términos de influencia discursiva y participación ciudadana, se vea medrada por la herencia

2 Para las perspectivas de la voz se recomienda revisar el texto El cuerpo de la voz de Francine Masiello. 
del desplazamiento y la mantención de la voz del padre por sobre la consciencia juvenil dentro de este diseño de país heteropatriarcal. Con respecto a esto, es particularmente interesante hacer referencia al titular del diario virtual El Dínamo: "La reacción del papá DC de Gabriel Boric tras ácida columna de su hijo sobre el legado de Aylwin", evidenciando la posición de poder del padre que permite cuestionar los dichos de Gabriel Boric -ex dirigente estudiantil y actual diputado de la república- sobre el argumento de la juventud como posición atolondrada del sujeto, con respecto a las manifestaciones estudiantiles y la muerte del ex presidente de Chile, Patricio Aylwin.

Como es posible sospechar, la repetición paulatina del modelo deseado en las diferentes generaciones va fundando un agotamiento del mismo, situación por la cual emergen actores sociales que dinamizan la participación ciudadana insistentemente anestesiada, abriendo nuevas vertientes críticas de un sistema agotado y utilitariamente mantenido desde el poder. Esta situación recurrente de silenciamiento para la voz estudiantil y la permanencia de la representación tradicionalmente heredada, generó una saturación que hizo fugar a los(as) estudiantes de aquel imaginario, (re)presentándolos en diferentes espacios, pero ahora desde aquellos rasgos que escapaban del molde hegemónico. La situación política dictatorial y la democracia cuestionada de la posdictadura, construyeron el escenario ideal para que aquellas subjetividades estudiantiles que disentían del poder se visibilizaran -en muchos casos con altos costos personales y colectivos- y diferentes producciones culturales pudiesen armar discursos creativos desestabilizadores.

Al revisar diacrónicamente los últimos 15 años, mientras el ya mencionado "el baile de los que sobran" continúa sonando en los personal stereo, Walkman y radios de los ochenta y noventa; audiovisualmente intervienen el campo cultural documentales como La mala educación y películas como Machuca o El vals de los inútiles, entre otros; el teatro con Clase de Guillermo Calderón y más recientemente Liceo de niñas de Nona Fernández; las novelas de Alejandro Zambra, Señoritas en toma de Valeria Barahona, Incompetentes de Constanza Gutiérrez, Ricardo Nixon School de Cristian Geisse, entre otros(as),3 insisten en instalar la problematización sobre el silencio, el sentido de la representación de los(as) sujetos(as) y la participación efectiva de los estudiantes en sus escenarios educativos y entramados sociales. Crear cultura y promoverla en diferentes producciones es una agencia política de los(as) autores(as) por situar estas subjetividades menospreciadas dentro de un imaginario cuestionado.

Se atribuye una posición discursiva para problematizar la educación desde quienes participan en ella, pues quienes lideran y han encabezado el ministerio se

3 Es necesario destacar que, para los estudios culturales y literarios relacionados con imaginarios escolares, han sido fundamentales las investigaciones de Rubí Carreño, sobre todo el texto Memorias del nuevo siglo: jóvenes, trabajadores y artistas en la novela chilena reciente. 


\section{Adiós a las armas}

Despatriarcar América desde la cultura

mueven entre la economía, la medicina, el trabajo social, el derecho, distantes de la pedagogía. De aquí, por ejemplo, que no nos extrañe que hoy en los establecimientos educacionales existan mini tribunales de justicia detrás de la bandera de la convivencia escolar, haciendo que profesores y estudiantes traten de solucionar las consecuencias efectivas, afectivas y agresivas que viven en el currículum oculto de los(as) sujetos(as) escolares de una sociedad neoliberal, egoísta y posmoderna, que las aventuras políticas y estatales de distintas veredas ideológicas han sido incapaces de asumir como desafío sociocultural, acostumbrándose la cómoda reproducción de la desigualdad.

\section{La oportunidad disidente: sujetos(as) estudiantiles en Al sur de la Alameda}

Con respecto a la participación de la cultura como espacio para la construcción de la disidencia, es importante destacar que esta posee la particularidad de ser dúctil, reformularse y adecuar los soportes y registros con la motivación de mantener el discurso y el horizonte discursivo al que pretende llegar. En este sentido, y como búsqueda de nuevas formas de enunciación con las cuales favorecer la lectura crítica de muchos(as), el texto literario se modifica para incorporar ilustraciones y signos visuales que pretenden, por un lado, señalar que la cultura-literatura sigue viva, crea y se reformula, así como por otro lado, erigir otros soportes, dialogar con distintos registros que favorezcan, colaboren y desafíen a los(as) lectores(as).

Si el horizonte de la creación con respecto a los imaginarios escolares y la representación estudiantil está instalado en desestabilizar lo tradicional, para buscar formas de legitimar esas voces, el libro Al sur de la Alameda de Lola Larra y Vicente Reinamontes se posiciona como uno de los productos culturales que contribuyen con esa tarea cuestionadora. Esta novela gráfica se inscribe y escribe para dar continuidad al ingreso de nuevos soportes escriturales que aborden la problematización de los imaginarios escolares. El vínculo de los signos gráficos o ilustrados en compañía de un texto claro y sugerente desde la posición estudiantil favorecen y promueven diversas posibilidades de interpretación, sin quitar la base cuestionada relativa a la calidad de la educación escenificada textualmente en un colegio desde donde la tradición establecería que el movimiento estudiantil tenga bajo impacto. En el texto se menciona que "[] El Nacional, El Aplicación. Nosotros siempre hemos sabido de ellos, pero ellos no tenían ni idea de que existíamos. Hasta ahora, porque somos de los pocos colegios privados que se han sumado a las protestas y tomas que hay en todo Chile" (Larra 32). El desafío de la novela, planteado por los autores, se sitúa al establecer la crítica al sistema educativo desde un territorio escolar de administración particular, donde los estudiantes se preguntan el sentido de la participación ciudadana en una movilización estudiantil que pareciera no 
afectarles, en el entendido que esas subjetividades conviven dentro de una expectativa educacional asimilada a la propuesta social de la hegemonía.

La aventura creativa que ofrece $A l$ sur de la Alameda en términos ilustrativos también es desafiante pues apela a una estética del cartel, del anuncio y la consigna con que se diseñan los lienzos para marchar y gritar a la sociedad el descontento por una representación y sistema educativo que no les pertenece, del que no se sienten partícipes en derecho, sino que esa vinculación con la escuela está mediada por una decisión de mercado sustentada por el capital económico de quienes pueden pagar por un tipo de educación distinta a la oferta pública del estado. Por esta razón, el imaginario escolar narrado no se sitúa en la educación pública, sino desde un espacio articulado por el capital donde los consumidores/estudiantes esperarían ser alienados por la reproducción de una forma de ser estudiante que es correspondiente a la conveniencia ideológica.

El quiebre de la tradición representada de los estudiantes se produce de manera evidente con la toma del colegio, situación que puede ser menos desafiante porque existe una concepción en la que es posible comprender esta acción política, sin embargo, además se proyecta una propuesta discursiva a través del empoderamiento de los y las sujetos y sujetas adolescentes, quienes asumen responsablemente un lugar informado desde donde gestionar su voz dentro del diálogo sociopolítico en que participan otros grupos de estudiantes y colegios.

En este sentido, por ejemplo, la novela propone liderazgo para las subjetividades normalmente desplazadas en el imaginario heterológico que construye la sociedad, atribuyendo significativo valor enunciativo a una estudiante que guiará acciones y reflexiones fundamentales de la movilización sin conceder espacio a la masculinización de su identidad, sino que legitimando frente al colectivo su compromiso con la agencia política estudiantil desde la voz femenina. En las reflexiones finales del "diario de una toma” el narrador comenta: "Como les decía, eso fue hace mucho tiempo. Ahora, aunque sigo jugando fútbol, formo parte del Centro de Alumnos. Y Rafa también. Quién lo diría, ¿no? Paula es la presidenta, claro, era de suponer" (281), proponiendo desprejuiciar la participación en el mundo público de la mujer con roles designados por las lógicas conservadoras y prioritariamente masculinas, instalando la autoridad en una mujer. Asimismo, se amplifica la visión sesgada de la creencia clasificatoria de las personas que distanciaría un sujeto deportivo de una acción política en un centro de estudiantes, pues los personajes hacen dialogar ambos aspectos.

De la misma manera, se produce una fractura en la representación estudiantil masculina, pues participan de la narración personajes que no ingresan a las expectativas de la masculinidad hegemónica y que serían sistemáticamente desplazados a los márgenes de la comprensión, sin embargo, son subjetividades que poseen un 


\section{Adiós a las armas}

Despatriarcar América desde la cultura

lugar influyente dentro de la narración, a pesar de que su constitución como sujeto masculino adolescente es distante al prototipo 'macho alfa'.

\section{Conclusiones}

Las vías que se construyen en las propuestas creativas de estas narraciones que ficcionalizan espacios escolares pretenden, entonces, generar un puente crítico, una activación crítica de los lectores frente a la lectura de un imaginario escolar que hace visible el daño y/o el trauma; o pretende establecer ideas de fuga que no se alcanzan y generan el dolor de la promesa incumplida; o instalan diseños de fuga y discusión ideológica alcanzables que pretenden abrir espacios donde se posicione el discurso alternativo, como si la expresión "se acabó el duopolio" fuese parte de los eslogan de este último grupo de escuelas y colegios.

En este sentido, y desde los Derechos Humanos, los estudiantes, esos sujetos sobre los que el poder imprime material y simbólicamente su ideología, son a su vez la colectividad que se satura de una representación que los desplaza de la realidad y que se activa y materializa su disgusto en las calles, muros y salas de clases, para discutir las políticas del silencio y subalternización que tradicionalmente los(as) han afectado.

Los estudiantes se "emancipan desde lo distinto", en palabras de Roberto Echevarren, como alteridad empoderada para masificar sus voces y construir una colectividad posible de manejar un poder organizado con el cual discutir la representación impuesta. La lucha por la representación continúa y se intensifica mientras el desespero de la hegemonía favorece el incesante envío a la zona del despojo y promueve la categorización agresiva de los sujetos escolares y el control de sus cuerpos como respuesta al desespero por la imposibilidad de controlarlos(as).

La renuncia y/o desestabilización a esa representación es el rechazo a una forma de pensamiento. La propuesta es considerar la educación como una oportunidad (Freire, Giroux). Asimismo, es una renuncia a las formas instaladas para comprender la sociedad y su política agresiva, permitiendo elaborar caminos ciudadanos socializados donde los sujetos, en este caso estudiantes, construyan aquello que desean como sociedad, una propuesta de espacio donde su representación sea una (re)presentación, una nueva forma, participativa y, por lo tanto, un imaginario donde los sujetos se comuniquen en favor de constituirse como comunidad (Esposito) en que las otredades agredidas no vivan el calvario del trauma.

Narrar la escuela en $A l$ sur de la Alameda es un gesto creativo donde legitimar al otro es la consigna que se sitúa específicamente en permitir y proponer creaciones culturales donde los estudiantes, subalternos, desplazados, con participación condicionada, puedan enunciar e instalen su voz dentro de la construcción del diseño social, constituyéndose como una colectividad consciente de su ejercicio 
e influencia política, asumiendo las múltiples otredades que viven en sus cuerpos: Colegio privado, adolescentes, con comprensiones diversas de familia, con adultos castradores a quienes desafiar y gentiles a quienes admirar, instalados desde una posición categorizada como beligerante en concepciones ideológicas del poder.

En Al sur de la Alameda, el diario de una toma, los escenarios posdictatoriales son cuestionados al evidenciar que las decisiones estatales no avanzan hacia la construcción de políticas públicas reales de equidad, sino que se fomenta la reproducción de estirpes estudiantiles que serán los sustentos de las clases sociales del mañana, como si la concepción de movilidad social y aprendizaje se mantuvieran en el cómodo status quo que asegura le herencia del poder entre los mismos, viviendo en un postfeudalismo mediado por el capital.

La novela propone discutir con la sociedad de control desde los agentes sociales que la misma sociedad tradicional ha prejuiciado como inmadura y silenciable, en un diálogo mudo donde toda negociación es vana frente a la creencia que los estudiantes son subalternizables y, por lo tanto, se puede prescindir de sus ideas.

En esta creación, el texto y las ilustraciones están imbricadas en favor de elevar una voz disidente que posicione a los(as) estudiantes como sujetos(as) conscientes de sus contextos y, por lo tanto, capaces de problematizarlos buscando soluciones. Para ello, la gráfica emitirá un discurso donde los trazos, imágenes y colores transparenten los escenarios de movilización, mientras el texto escrito permita conocer la interioridad de los personajes y sus reflexiones en torno al diseño social y educacional. Incluso, de acuerdo a la perspectiva del lector, la novela gráfica permite que la actualización del texto literario se amplifique y al dialogar diferentes lenguajes en el mismo discurso es posible que aquellos(as) que leen la novela puedan ingresar desde aquella arista interpretativa que más les facilite.

En este sentido crítico, esta novela gráfica diversifica y permite establecer diálogos en torno a las concepciones tradicionales de masculinidad, desestabilizando la rigurosidad de la herencia cómoda de formación desvinculada de sujetos productivos irreflexivos fanáticos por el poder y la decisión de otros sobre sus cuerpos y vidas. De esta manera, se produce un desplazamiento de la autoridad hacia la configuración de una masculinidad alternativa que decide construir su representación pública en una estudiante, así como también se desinstala el prejuicio y se reconocen las habilidades políticas de jóvenes deportistas como agentes válidos para la representación de la colectividad estudiantil en el Centro de Estudiantes.

Legitimar parece ser el concepto que complejiza la propuesta de este artículo, sin embargo, el impacto de esta palabra dentro de las posibilidades de modificación cultural es profundo y la explicación que sustenta la necesidad de incorporarla dentro de nuestras acciones políticas, docentes e investigativas está frente a nosotros cada día. Legitimar es comprender que soy con el otro(a) y que no puedo ser sin el otro(a), por lo tanto debo conocerlo íntegramente antes de juzgarlo y violentarlo. 


\section{Adiós a las armas}

Despatriarcar América desde la cultura

La necesidad de legitimar al otro(a), no tan solo en Chile, es cada vez un desafío más urgente y lo evidencio de la siguiente manera: Durante el 2016 se vertieron miles de litros y kilos de basura tóxica al mar en Chiloé; las celulosas siguen descargando sus emisarios químicos en las costas chilenas, alimentando con veneno los peces, crustáceos y moluscos que muchos(as) chilenos(as) comerán en sus hogares; se continuó violentando estudiantes en las manifestaciones, usando los tradicionales vehículos disuasivos (guanaco y zorrillo) que en el resto del mundo están prohibidos por atentar contra los DD.HH. de todos(as) los ciudadanos, las mismas fuerzas especiales con las que se reprime a los pobladores y pescadores de Chiloé y que también operan en el genocidio estatal contra el pueblo mapuche; más de cincuenta mujeres han sido víctimas de agresión y muchas de ellas han terminado en feminicidios donde incluso son asesinados los hijos. Destaco el caso de Nabila Rifo, mujer de la región de Aysén que fue fracturada en múltiples partes de su cuerpo y además le quitaron los ojos en un acto de violencia de pareja; los niveles de agresión esporádica y bullying por diferentes causas sigue siendo una rutinaria y cruel realidad para muchos(as) estudiantes del sistema escolar de Chile. La violencia continúa siendo el saludo sociocultural de nuestro país y mientras así sea existe una resistencia frente al reconocimiento de la otredad.

Si tuviésemos incorporada la consciencia de la legitimación y la necesidad de políticas de DD.HH. en los procesos de formación ciudadana, podríamos pensar que existiría un ecosistema equilibrado en el que puedan coexistir las futuras generaciones, un diálogo transparente con el imaginario y tradiciones indígenas, creeríamos en el valor de la voz ciudadana más allá de las redes sociales y las elecciones para distintos cargos sin que la indignación sea explosiva y las leyes y decisiones emergentes solo remediales, y confiaríamos en que nuestros(as) jóvenes estudiantes son capaces de tener una voz consciente y profunda con respecto a las problemáticas que nos afectan como sociedad.

Ficcionalizar la escuela, en definitiva, es una insistencia creativa de los autores por presentar construcciones culturales que motiven otras opciones constitutivas de sociedad, otras oportunidades de sociedad, en un ejercicio de confianza con el lector -actualmente anestesiado de participación ciudadana- para estimular las posibilidades críticas 4 y que el ejercicio de la lectura sea, a su vez, una lectura de la sociedad, una sociedad posible y proyectada hacia un diseño de legitimación donde participen comprometidamente diferentes sujetos y no los sujetos diferentes.

La elección ganada por Sharp es la activación de la colectividad y una agencia política empoderada que desestabiliza la orgánica tradicional de la política, pues como menciona María Emilia Tijoux "La política surge cuando los excluidos no

4 Destaco una cita de Jacques Ranciere en la Política de la Literatura: "Pero las interpretaciones en sí son cambios reales, cuando alteran las formas de visibilidad de un mundo común y, con ellas, las capacidades que los cuerpos ordinarios pueden ejercitar sobre un nuevo paisaje de lo común” (54). 
son contados como parte social, denuncian la injusticia de la igualdad que funda la sociedad democrática, instituyendo el litigio" (17).

Los(as) autores de estas novelas pretenden motivar la preocupación y la inquietud de los lectores por reconfigurar el actual diseño social violento. "se acabó el duopolio", dicho en la calle, en la hoja gris donde las personas escriben cotidianamente con sus cuerpos es la confirmación de una vía alternativa posible, un gesto político evidente que la cultura ha mencionado hace años y que estas novelas seleccionadas conflictúan desde la escuela.

Narrar la escuela y enunciar colectivamente desde el espacio público, situados fuera del colegio de profesores, es un gesto indicial que instala el cambio en los escenarios educativos, desde donde es posible aventurar un viraje inicial hacia la real legitimación de los sujetos, que es, dentro de muchas consideraciones, uno de los Derechos Humanos fundamentales. Como señala la cantante rapera chilena Anita Tijoux, es constituyente de derecho "Caminar seguro, libre y sin temor, respirar y sacar la voz". 


\section{Obras citadas}

Althusser, Louis. Ideología y aparatos ideológicos del estado. Quinto Sol, 1987.

Barahona, Valeria. Señoritas en toma. Emergencia Narrativa, 2016.

Bourdieu, Pierre. La reproducción. Elementos para una teoría del sistema de enseñanza. Popular, 2001.

Cajas, Edison. El vals de los inútiles. Cusicanqui Films, 2013.

Calderón, Guillermo. "Clase”. Teatro 1: Neva / Diciembre / Clase. lom, 2012.

Carreño, Rubí. Leche amarga: violencia y erotismo en la narrativa chilena del siglo xx. Cuarto Propio, 2007.

- Memorias del nuevo siglo. Jóvenes, trabajadores y artistas en la novela chilena reciente. Cuarto Propio, 2009.

. Av. Independencia. Literatura, música e ideas de Chile disidente. Cuarto Propio, 2013.

. "Chile en marcha: literatura, música y movimiento estudiantil". E-mispherica,

no. 102, https://hemisphericinstitute.org/en/emisferica-102/10-2-dossier/chile-enmarcha-literatura-musica-y-movimiento-estudiantil.html

Connell, R.W. "La organización social de la masculinidad". Masculinidad/es. Poder y crisis, editado por Teresa Valdés y José Olavarría, Isis Internacional, 1997, pp. 31-48.

El Dínamo. "La reacción del papá DC de Gabriel Boric tras ácida columna de su hijo sobre el legado de Aylwin”. El Dínamo, 21 abril 2016, http://www.eldinamo.cl/ nacional/2016/04/21/boric-padre-columna-aylwin-critica-decepcionante/

Fernández, Nona. Space Invaders. Alquimia, 2013.

. Liceo de Niñas. Oxímoron, 2016.

Foucault, Michel. Vigilar y castigar. Nacimiento de la prisión. Siglo xxi. 2009.

Geisse, Cristian. Ricardo Nixon School. Planeta / Emece. 2016.

Gutiérrez, Constanza. Incompetentes. La pollera. 2014

Kohan, Martin. Ciencias Morales. Anagrama. 2007

Larra, Lola y Reinamontes, Vicente. Al sur de la alameda. Diario de una toma. Ekaré. 2014.

Lemebel, Pedro. Háblame de amores. Seix Barral, 2012.

Los prisioneros. "El baile de los que sobran". Pateando Piedras. Emi-Odeón, 1986.

Masiello, Francine. El cuerpo de la voz: poesía, ética y cultura. Beatriz Viterbo. 2013.

Neruda, Pablo. "Walking around". Antología general de Pablo Neruda. rae, 2010.

Ranciere, Jacques. Política de la literatura. Libros del zorzal, 2011.

Sharp, Jorge. "El independiente Jorge Sharp da la gran sorpresa en Valparaíso". YouTube,

23 octubre 2016, https://www.youtube.com/watch?v=RNJPo3hRvBE

Spivak, Gayatri. ¿Puede hablar el subalterno?, traducido por José Amícola. El cuenco de plata, 2011.

Tijoux, María Emilia. "Presentación”. El viraje ético de la estética y la politica de Jacques Ranciére.

Palinodia, 2005.

Tijuox, Ana. "Sacar la voz". La bala. National Records, 2011.

Wood, Andrés. Machuca. Andrés Wood Producciones, 2004.

Zambra, Alejandro. Formas de volver a casa. Anagrama, 2011. 